Article

\title{
Parents' Views of a Classroom and Closed-Road Post-License Driving Program for Teen Drivers, Guard Your Life
}

\author{
Lauren Mims ${ }^{1}$, Johnell O. Brooks ${ }^{1, *}$, Casey Jenkins ${ }^{1}$, Breno Schwambach ${ }^{1}$ and \\ Daniel Gubitosa ${ }^{2}$ \\ 1 Department of Automotive Engineering, Clemson University, Greenville, SC 29607, USA; \\ lmims@g.clemson.edu (L.M.); caseyj@clemson.edu (C.J.); bschwam@g.clemson.edu (B.S.) \\ 2 BMW Performance Center, Greer, SC 29651, USA; Daniel.gubitosa@bmwna.com \\ * Correspondence: jobrook@clemson.edu; Tel.: +1-864-283-7272
}

Received: 28 September 2020; Accepted: 16 December 2020; Published: 18 December 2020

check for updates

\begin{abstract}
In the US, teenage drivers have an increased risk of being involved in crashes. To address this, post-license advanced driving programs have emerged. This study gains parents' perspectives while observing their teens' involvement in a post-license driving program focused on a hands-on introduction to emergency braking, skid recovery and the dangers of distracted driving. Parents completed a survey after the program, and for comparison purposes, the teens also completed a survey at the end of the program. While the parents only observed the program, the results revealed that most learned useful information and would consider additional training for themselves. Almost all teens and parents reported anticipating changing their driving behaviors, specifically by reducing distractions, having a heightened awareness and changing their driving position. These results suggest that parents benefited from simply observing the class.
\end{abstract}

Keywords: parent attitudes; teen drivers; defensive driving; emergency braking; skid recovery; distractions

\section{Introduction}

In the US, parents are often vital to a teenager when developing driving skills and gaining driving privileges. Parents typically have a significant role in the responsibility of teaching their teens to drive. Once a teen is licensed, parents are responsible for setting boundaries and restrictions on their teens' driving privileges. The majority of research involving parents and their teen drivers has focused on these restrictions. With the emergence of post-license driving programs, it is unknown how parents view these programs or if there are benefits to parents attending these programs with their teen. The current study investigates a half-day program starting with a classroom portion, followed by an on-track portion, where the teens practice engaging the anti-lock braking system (ABS), recovering from a skid, and experience the dangers of driving distracted. The parents are strongly encouraged to attend the classroom portion and the majority stay to watch the track portion.

\subsection{Parents' Role in Their Teen's Driving Experience}

Parents typically play a critical role in their teens' driving development. Parents make important decisions that directly impact their teens' driving behaviors, from teaching their teen how to drive, to establishing boundaries and rules once the teen is driving independently, and to enrolling their teen in a post-licensure course.

For a teen that is under the age of 18, driver's education requires on average of six hours of driving time with a "professional" driving instructor, to gain basic vehicle maneuvering skills [1]. As part of 
the graduated driver's license in many states, parents are required to provide about $50 \mathrm{~h}$ of supervised practice with their teen driver [2].

The majority of the teaching needed for independent driving is intended to be completed by the parents. This also means parents need to teach higher-order skills such as hazard detection and risk perception, because teens will likely not have sufficient time with the driving instructor to develop these skills [1]. Though teens need these higher-order skills, little is known about what and how parents teach their teens when teaching them to drive [1]. A study conducted to gauge parent's views on implementing $50 \mathrm{~h}$ of supervised practice showed that nearly all parents had a good experience with the graduated licensing program, and most parents thought $50 \mathrm{~h}$ was the right amount of practice [3]. A study conducted by Mayhew, Simpson, and Pak [4] showed that crash rates during supervised practice were much lower when compared to newly licensed teens driving independently.

If a teen driver has passed the on-road driver's test and is under the age of 18, many states grant licenses with restrictions. The restrictions vary by state but often include limitations on the number of passengers, curfew [2], and/or cell phone use [5]. Restrictions target some of the most common causes for crashes. Driver error is the most common cause of teen crashes, especially distraction, which accounts for $9 \%$ of all teen crashes in the US [6]. Some of the most common types of crashes teens experience are single vehicle run-off-road crashes on both straight and curvy roads, rear-end collisions, and turning into an oncoming vehicle in an intersection [7]. Acknowledging that the first few months after licensure produce the highest crash rates [4], most of the research involving teen driver's parents has focused on parents' perception of risk and the effects of establishing boundaries during the first months after licensure.

It has been shown that teens with parents who set stricter boundaries for their teen, including limiting teen passengers and nighttime driving, had lower crash and violation rates than teens with fewer restrictions [8]. Unfortunately, most parents only set modest boundaries that last for a short period of time. Hartos, Eitel, Haynie, and Simons-Morton [9] found that teen drivers who had their license for a year or more had fewer parental restrictions than those who had their license for less than a year. Even for parental restrictions lasting a year, these restrictions are often shorter than the duration of the restricted license period. Many parents fail to understand some of the greatest risks associated with newly licensed teens, such as teenage passengers [10]. A study that interviewed teens and parents separately showed the disconnect between the parents' and teens' expectations regarding driving privileges. The greatest disconnects between teens and parents were the expectations for the number of approved destinations, unlimited vehicle access, curfew and the number of teen passengers, where teens expected greater freedom and a lower number of restrictions than what their parents reported [11].

There is limited information on parent involvement in the first few months after licensure, and even less information on parent involvement or parent perspective in post-license training focused on developing higher-level skills.

\subsection{Post-License Driving Programs}

Due to the nature of the licensure process in the US, post-license driving programs have emerged to provide drivers with additional behind-the-wheel experience beyond typical driver's education or parent-supervised practice. Many of these post-license programs focus on defensive or emergency skills that utilize the vehicle's safety systems, such as electronic stability control or anti-lock braking systems, as well as the dangers of distracted driving. These post-license programs exist world-wide and, in some cases, are even a license requirement [12]. The benefits associated with these post-license programs have been debated. Some researchers have found that advanced driving programs focused on skill mastery can lead to higher crash rates [13-15], while others have identified reductions in crash rates and/or violations in programs that focus on insight and awareness training [12,16]. There is simply conflicting evidence for these programs, where some suggest overconfidence in their abilities after participating in a post-license driving program [17-19], others suggest the opposite [20], and some 
have no effects [21]. New drivers do have the tendency to become safer as they gain experience [22], which could be why some studies demonstrate an increase in self-efficacy and lowered risk perception. Further investigation into post-license driving programs is needed to better understand their benefits and limitations.

\subsection{Guard Your Life Challenge Program}

The Guard Your Life (GYL) Challenge program was started by the Humphries family after they lost their teenage daughter, Victoria, in a single vehicle crash in July of 2012. She lost control of her vehicle at night and ran off the road, similarly to many other single-vehicle teen fatalities. The Guard Your Life (GYL) Challenge program (http://www.guardyourlifechallenge.com) is a non-profit, post-license driving program for teens. The program is held at a local performance driving center and focuses on introducing teens to emergency braking using ABS, skid recovery and the dangers of distracted driving (Figure 1).

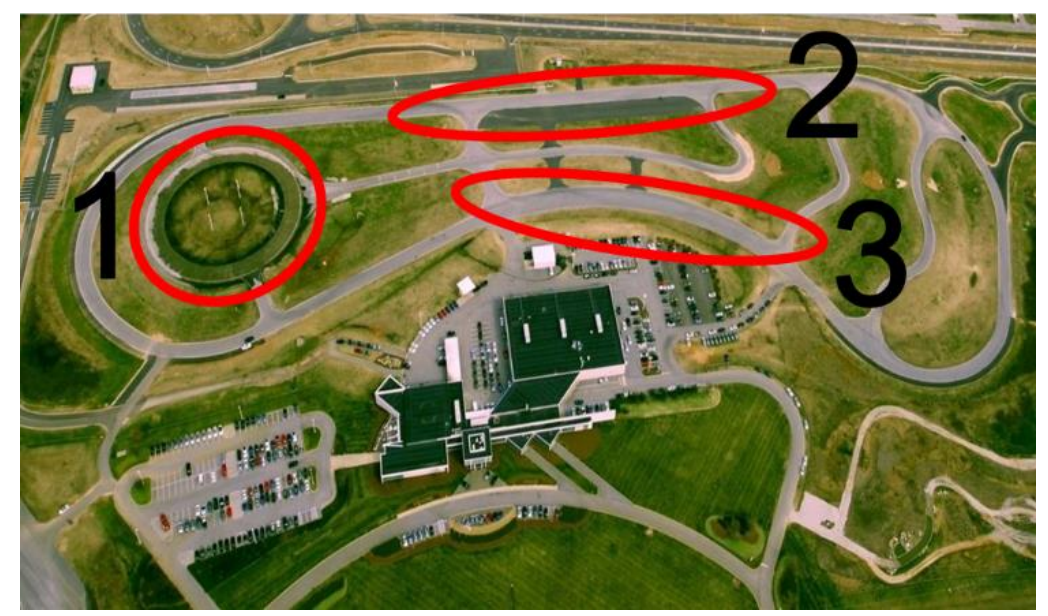

Figure 1. Aerial view of the track with the locations of the (1) skid recovery, (2) ABS braking, and (3) distraction exercises indicated.

The program begins in the classroom before moving to exercises on a closed-road track. The parents are encouraged to stay for the classroom portion and the majority stay to watch the driving portion. The classroom portion consists of an introduction to the family and their story, followed by a spokesman from the state's Highway Patrol, who speaks about teen crash and fatality statistics. The officer gives a detailed explanation of the physics behind what happens to an individual's body and brain during a crash as well as the components of distracted driving [23]. The spokesman often engages the parents in the discussion, so the parents acknowledge they are modeling driver distraction behaviors to their children (i.e., eating or drinking a beverage while driving, checking their phone for a work message), to demonstrate what a distraction is and how their behaviors can set poor examples for their teens.

Instructors from the performance center provide short introductions, including their years of experience and professional racing licenses held. The lead instructor then provides an overview of basic behaviors and adjustments needed for optimal positioning in the driver's seat. The instructor goes over the proper place to look out the windshield while driving as well as how to position the side and rearview mirrors to eliminate blind spots. Then, the instructor provides an introduction to ABS that will be part of the emergency braking exercise, oversteer, understeer, and how to anticipate and make corrections in a loss of traction situation on the skid pad. The instructor finishes the classroom portion by giving an overview of the track and the three exercises. Next, the teens are divided into groups and rotate through the various exercises on the closed-road track (Figure 2). 


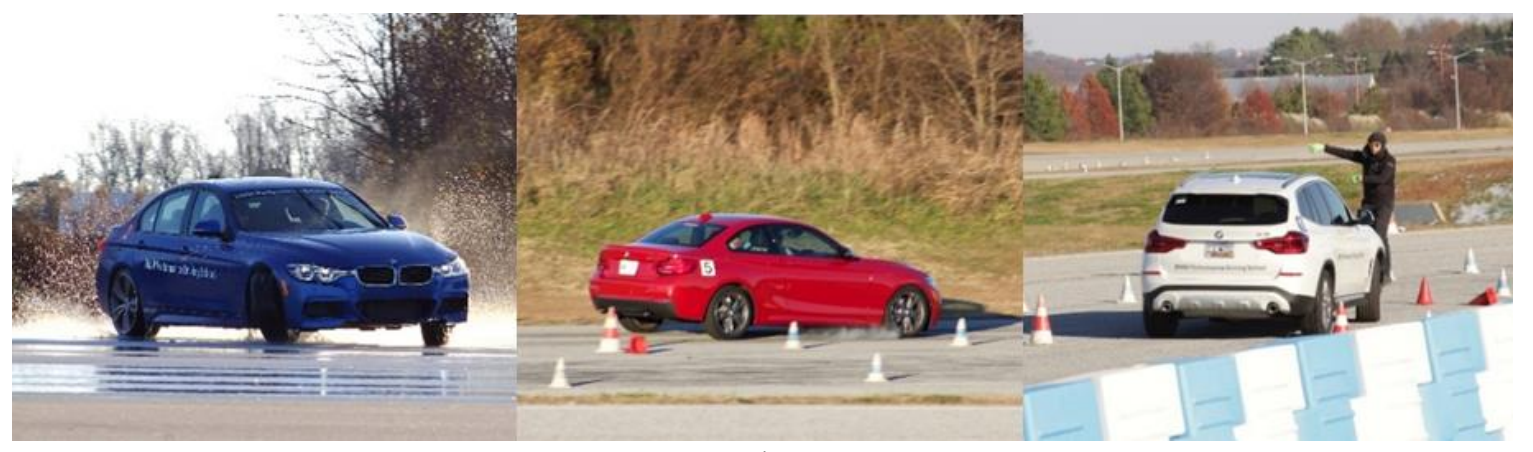

(a)

(b)

(c)

Figure 2. (a) a teen driver learning how to recover from a skid, (b) a teen driver activating the ABS brakes, and (c) a teen driver completing the distraction exercise with an instructor on the track providing feedback.

A previous study examined the teens' views of GYL directly after the program through a survey, and three months after through a phone interview [24]. The results from both the survey and phone interview reflected the overarching concepts the teens were introduced to during the program. The results from the survey showed that the teens learned about behaviors such as where to look while driving and proper seating positioning, as well as ABS braking and skid recovery. The results reported during the phone interview showed that most of the participants (72\%) used the skills on the road. The most common skills reported as being used were ABS braking, skid recovery and reducing distractions. Half of the teens who completed the phone interview reported avoiding a crash using the skills taught, where ABS braking was the most common skill reported. Responses from the phone interview also suggest that $92 \%$ of participants reported changing their behaviors after the program. The most commonly changed behaviors reported were reducing distractions, driving with heightened awareness and changing their driving position. Overall, from the survey and phone interview the teens reported benefitting from the behaviors and skills introduced by the GYL program.

The GYL program encourages parents to stay for the classroom portion of the program. After observing how attentive the parents were during the classroom portion and the number of parents who stayed to watch the track portion, gaining the parents' views of the program was naturally the next step. For this follow-up study, teens and parents were recruited to participate in a survey that was completed after the GYL program to gain parent's perspectives on the program, parents' beliefs on what they believed their teens gained from the program, and teen's perspective of the program for comparison purposes.

\section{Methods}

\subsection{Participants}

Teen and parent participants were recruited after the completion of the previous GYL study with the teens [13], from the eight following consecutive GYL sessions. Of the 225 teens from those eight sessions, 164 completed the survey. Teen participants included 91 males and 72 females with an average age of 16.4 years old, ranging from 15 to 19 years old (SD =1.06). A total of 134 parents completed the survey, including 60 males and 74 females. There were no identifiers on the surveys to link a parent and their teen together.

\subsection{Procedure}

All subjects read the consent form and provided their written approval prior to participating in this study. Since many of the participants were teenagers, all participants under the age of 18 years had written permission from a parent. This study was conducted in accordance with the Declaration of Helsinki and the protocol was approved by the Ethics Committee at Clemson University (IRB2015-258). 
Directly after the driving portion of the program, teens and parents return to the classroom for closing remarks and to complete the surveys. The surveys took between 10 and $15 \mathrm{~min}$ to complete.

Since the focus of this study was on the parents' perspective of their own behavior as well as that of their teen, the teens' survey data were used for comparison. The survey questions for both the parents and teens are shown in Table 1. With the exception of yes/no questions, the majority of the questions were open-ended.

Table 1. Parent and teen survey questions.

\begin{tabular}{|c|c|c|}
\hline Parent & Teen & Questions \\
\hline & $\mathrm{x}$ & What is your age? \\
\hline$x$ & $x$ & What is your gender? \\
\hline $\mathrm{X}$ & & Have you ever activated the ABS braking system while driving? \\
\hline $\mathrm{X}$ & & Have you ever experienced a skid? \\
\hline $\mathrm{x}$ & & Did you teach your teen about ABS braking before today's program? ${ }^{*}$ \\
\hline $\mathrm{X}$ & & Did you teach your teen about recovering from a skid before today's program? ${ }^{*}$ \\
\hline$x$ & & Did you teach your teen about distracted driving before today's program? ${ }^{*}$ \\
\hline $\mathrm{x}$ & $\mathrm{x}$ & Do you think you will change any of your driving behaviors as a result of the program? \\
\hline $\mathrm{x}$ & $\mathrm{x}$ & What is the most important thing you learned? \\
\hline $\mathrm{x}$ & & What is the most important thing your teen learned? \\
\hline $\mathrm{X}$ & & Do you plan on discussing any of the topics that were discussed during the program with your teen? \\
\hline $\mathrm{X}$ & & After seeing the training your teen went through, would you consider additional driver's training for yourself? \\
\hline
\end{tabular}

\section{Data Organization}

For each question, teen and adult responses were separated. Then all of either the teen or adult participants' responses were combined and sorted by grouping similar responses together. As the responses were sorted and grouped, categories were formed. These categories turned into topical areas; for example, the topical area of ABS braking represents responses such as brake hard, stomp on the brake and emergency braking. The number of responses for each topical area were tallied to determine the most common responses. Then, the topical areas were compared between the teens and adults.

\section{Results}

\subsection{Parents' Driving Experience}

Parents were asked if they had any specialized driver training, and $11 \%$ of the 125 parents that responded said they had specialized driver training. When asked what training they had experienced the most common responses were classes from BMW or similar defensive driving courses $(36 \%)$, amateur and professional racing $(21 \%)$, training through the DOT or DMV $(14 \%)$, and 40 or more years of driving experience $(14 \%)$.

Parents were asked if they had ever activated ABS and $85 \%$ of the 119 parents that responded had experienced ABS previously. When asked if they had been trained to activate ABS, $31 \%$ of the 128 parents had experienced training, although only 20 of the 40 participants who said they had been trained to activate ABS reported the place or person they were trained by. The most common responses to where were you trained or whom were you trained by were BMW $(36 \%)$, their father $(18 \%)$ and reading about ABS (9\%).

Parents were asked if they had ever experienced skidding while driving and $92 \%$ of the 128 parents who responded had experienced skidding. Parents were also asked if they had been trained to recover 
from a skid, where $38 \%$ experienced training. Of the 48 participants who said they had been trained to recover from a skid, 35 reported the place or person they were trained by. The most common places or people the parents were trained by were BMW $(17 \%)$, a parent or family member $(17 \%)$ and driver's training $(9 \%)$.

\subsection{Parents Teaching Their Teens to Drive}

Parents were asked if they were the primary parent that taught their teen to drive. Of the 134 participants, 133 parents responded either yes or no. In total, 73\% of parents responded "yes" and $27 \%$ of parents responded "no".

Parents were asked if they taught their teen about ABS before the program. Of the 134 participants, 74 parents responded either yes or no. In total, $53 \%$ of parents responded "yes" and $27 \%$ of parents responded "no". The parents who said they had taught their teen about ABS were asked to select the method they used. The options for method used were "discussion" and "hands-on practice". Of the 39 parents who taught their teen about ABS, 30 parents selected a method. The majority (87\%) had a discussion with their teen about ABS and $13 \%$ of parents reported hands-on practice.

Next, parents were asked if they taught their teen about skid recovery. Only $37 \%$ of the 73 parents who responded said they taught their teen about skid recovery. When asked what method was used when teaching their teen about skid recovery, 25 of the 27 parents responded. The most common method used to teach their teen about skid recovery was discussion (92\%), and only $8 \%$ used a hands-on practice method.

Parents were also asked if they taught their teen about distracted driving. Of the 74 parents who responded, $89 \%$ said they had taught their teen about distracted driving before the program. The majority ( $96 \%$ ) of the parents had discussions with their teen about distracted driving, and few (4\%) parents used hands-on practice.

\subsection{Possible Positive Effects of the Program}

Parents were asked if they thought they would change their own behavior after observing the program. Of the 134 participants, 113 parents responded either yes or no. In total, $81 \%$ of parents responded "yes" and 19\% of parents responded "no". Of the 92 parents that responded "yes", they were asked to indicate which behaviors they would change. Of the 77 parents that responded with a behavior, categories included: reduce distractions (31\%), all/multiple behaviors $(23 \%)$, skid recovery ( $8 \%$; skid recovery is not a behavior but was among the top five responses given by parents), pay attention $(7 \%)$, seat position $(7 \%)$ and other $(23 \%$; all "other" topics were only mentioned by less than $5 \%$ of parents or only one parent).

Parents were asked if they thought their teen would change their driving behaviors as a result of the program. Of the 134 participants, 124 parents responded to this question, with $96 \%$ responding "yes" and 4\% responding "no". For those parents who thought their teen would change their behavior, they were asked what behaviors they thought their teen will change. Of the 119 parents that thought their teen would change their behavior, 90 parents gave specific behaviors. Some of the most common responses were categorized into the following topical areas: reducing distractions (24\%), more aware $(14 \%)$, all/multiple topics $(10 \%)$, look further ahead $(9 \%)$, and more confidence $(7 \%)$. The remaining $36 \%$ were "other" topics provided by less than $5 \%$ of parents or only one parent.

Both the teens and parents were asked to write the top three things that they had learned during the program. On the parent survey, parents were asked what they learned and what they thought their teen learned. There were 123 parents that gave responses for the top three things they learned, totaling 274 responses. Parents on average gave 2.0 responses with a range of 1 to 3 responses (SD $=0.8$ ). In total, 125 parents provided responses for the top three things they thought their teen learned, with a total of 275 responses. The average number of responses was 2.1, ranging from 1 to 3 responses $(\mathrm{SD}=0.8)$. A total of 160 teens responded, providing 465 responses. The average number of responses given by the teens was 2.8 , with a range of 1 to $3(\mathrm{SD}=0.3)$. 
The parents reported that the most important things they learned fell into the topical areas of seat/hand position (22\%), looking where they want to go $(14 \%)$, braking $(8 \%)$, skid recovery $(8 \%)$, and distractions (8\%). All "other" topics (40\%) were mentioned by 5\% or less of parents, or one parent. Parents anticipated that their teen learned about the following topical areas: skid recovery $(22 \%)$, braking (19\%), distractions $(14 \%)$, confidence $(8 \%)$, and experience with unexpected situations $(6 \%)$. The remaining "other" $(31 \%)$ topics were mentioned by $5 \%$ or less of parents, or one parent. Teens reported learning from the following topical areas: braking (20\%), skid recovery (18\%), distractions $(17 \%)$, looking where they want to go $(6 \%)$, and education $(5 \%)$. The remaining "other" $(34 \%)$ responses were mentioned by less than $5 \%$ of the teens or one teen. These results are shown in Table 2.

Table 2. Top three things learned for the parent's response, parent's anticipated response for their teen, and the teen's response.

\begin{tabular}{cccc}
\hline Topics & $\begin{array}{c}\text { Parent's Response } \\
\text { for Self }\end{array}$ & $\begin{array}{c}\text { Parent's Anticipated } \\
\text { Response for Their Teen }\end{array}$ & Teen's Response \\
\hline Seat/hand position & $22 \%$ & $3 \%$ & $2 \%$ \\
\hline Look where want to go & $14 \%$ & $5 \%$ & $6 \%$ \\
\hline Braking & $8 \%$ & $19 \%$ & $20 \%$ \\
\hline Skid recovery & $8 \%$ & $22 \%$ & $18 \%$ \\
\hline Distractions & $8 \%$ & $14 \%$ & $17 \%$ \\
\hline Education & $2 \%$ & $0 \%$ & $5 \%$ \\
\hline Confidence & $1 \%$ & $8 \%$ & $3 \%$ \\
\hline $\begin{array}{c}\text { Experience with } \\
\text { unexpected situations }\end{array}$ & $0 \%$ & $6 \%$ & $0 \%$ \\
\hline
\end{tabular}

Participants on both the teen and parent surveys were asked to report the most important thing they learned during the program. On the parent survey, parents were asked what they thought was the most important thing their teen learned. In total, 121 parents and 155 teens responded. The most important things parents thought the teens learned included skid control (18\%), handling different situations encountered when driving (12\%), ABS braking (12\%), improved driving skills (10\%) and distractions (9\%). All "other" (39\%) topics were mentioned by $7 \%$ or less of parents or one parent. Teens thought the most important things they learned fell into these topical areas: skid control (56\%), ABS braking (16\%), looking where you want to go $(7 \%)$, distractions $(7 \%)$, and staying calm $(4 \%)$. All "other" (10\%) topics were mentioned by $2 \%$ or less of teens, or one teen. These results are shown in Table 3.

Table 3. Most important thing learned for the parent's anticipated response for their teen and the teen's response.

\begin{tabular}{ccc}
\hline Topics & Parent's Anticipated Response for Their Teen & Teen's Response \\
\hline Skid control & $18 \%$ & $56 \%$ \\
\hline Handling different situations & $12 \%$ & $0 \%$ \\
\hline ABS braking & $12 \%$ & $16 \%$ \\
\hline Improved driving skills & $10 \%$ & $0 \%$ \\
\hline Distractions & $9 \%$ & $7 \%$ \\
\hline Look where you want to go & $6 \%$ & $7 \%$ \\
\hline Staying calm & $3 \%$ & $4 \%$ \\
\hline
\end{tabular}

On the parent survey, participants were asked if they were planning on discussing any of the topics taught during the program with their teen in the future. Of the 127 parents that responded, 
98\% responded "yes" and $2 \%$ responded "no". The 125 parents who planned on discussing topics from the program were then asked which topics they planned on discussing. Of the 125 parents, 104 responded with a specific topic. The most common topics given were all/multiple topics (63\%), reducing distractions (14\%) and skid recovery $(6 \%)$; some parents wanted to ask their teen what they learned during the program (5\%), and "other" $(12 \%)$ was mentioned by less than $5 \%$ of parents or one parent.

Parents were asked after observing their teens throughout the program if they, the parent, would consider additional training for themselves. Of the 115 parents that responded, $70 \%$ would consider additional training and $30 \%$ would not.

\section{Discussion and Conclusions}

The goal of conducting this study was to gain the parents' perspectives of the half-day post-license driver's training program, Guard Your Life (GYL). This program begins in the classroom with an introduction to the professional driving instructors. The classroom portion includes instruction on the importance of knowing where to look, proper hand and seating position, mirror adjustment to minimize blind spots, oversteer and understeer corrections, the purpose of the anti-lock braking system (ABS), and the dangers of different types of distraction. The teens then get behind-the-wheel experience on a closed-road course with ABS braking, skid recovery and distracted driving. Parents and teens completed a survey directly after the class to gain the parents' perspective in addition to the teens' perspective of the program. The inspiration for this study came from observations of parents at previous GYL events, where the focus was only on the teens' view of the program [24]. During the classroom portion of the program, parents were engaged and the majority stayed to watch the track portion of the program.

The results of the parent survey showed that most parents do not have specialized driver's training even though most parents have experienced ABS and a skid. When it came to teaching their teen to drive, about half of the parents taught their teens about ABS and even less taught their teen about skid recovery. Most of the parents reported talking to their teens about distractions. Though parents said they taught their teens about these topics, the overwhelming majority only had discussions with their teen.

The majority of parents thought they would change their behavior based on what they observed during the program, including reducing distractions, paying more attention and changing their seating position. These results show that the information from the classroom portion of the program may not have been known or incorporated into the parents' daily driving behaviors before the class. The behaviors the parents reported that they will change in the future are consistent with the behaviors the teens in the previous study reported changing three months after the GYL program [24]. This suggests that not only teens, but also parents, can benefit from these types of programs.

It is well documented that there are differences between male and female drivers, where male drivers of all ages are consistently involved in more fatal crashes than female drivers [25]. Similar to trends seen with teen drivers when compared to adult drivers, males show riskier driving behaviors than female drivers [26]. Responses between both genders for the teen and parent populations were investigated for potential differences. The teens' most common responses for both the top three topics they got from the program and the most important topic from the program were the same for males and females. This same trend was observed in the male and female parents.

When exploring other potential differences between male and female parents, one of the biggest differences between the genders was when parents were asked if they would change their behaviors as a result of the program. For the parents that indicated they anticipate changing their behaviors, $35 \%$ were fathers and $65 \%$ were mothers. Other interesting observations with the parents included the numbers that had had specialized driver training, where $64 \%$ were fathers and $36 \%$ were mothers. With previous experience activating ABS and skidding, approximately half were fathers and half were mothers. Overall, the fathers and mothers had similar experiences out on the road. Of the parents who 
had reported previous ABS or skid training, approximately 60\% were fathers. A higher percentage of the mothers (58\%) would consider additional training for themselves after observing their child experience the program. Interestingly, though there was a similar number of male and female parents that participated, the mothers often completed more of the survey than the fathers.

In the US, the majority of the responsibility when it comes to teaching teens to drive falls onto the parents. Parents are models of behavior, so if a parent is driving distracted or in an incorrect driving position, it is possible the teen will exhibit the same behavior.

The results show that the majority of parents reported that after observing their teen complete the GYL program, they would consider additional driver's training for themselves. This may indicate that after observing the program, parents did not feel they were proficient in the skills taught in the program.

It is not clear exactly what parents teach their teens when learning to drive, but research suggests that parents typically focus on basic skills in controlled environments, not necessarily in the environments they will be driving in post-licensure [27]. It is unknown if parents teach these basic skills because they think they are the only necessary skills their teen needs to learn to drive, or if it is because parents do not have the skills or resources to teach teens higher-order skills.

\section{Study Limitations}

This study gave insight into the teens' and parent's views of the GYL program, but there were limitations. This study was conducted through self-report surveys. There were no performance data collected, so it is unknown if the teens or adults improved their driving skills. There was no follow-up after the program, so it is unknown if teens and parents actually changed their behavior or participated in additional training. The other limitation of this study is the parent population. Due to the fact that post-licensure training is not a requirement in the US, parents that sign their teen up for the GYL program are interested in having their teen become a safer driver, acknowledging that additional training beyond driver's education may be beneficial. This view may not be consistent with all parents.

\section{Future Research}

Future research should focus on incorporating follow-up surveys to determine if there were any long-term effects on the parents' behavior. In the future, it is also important to understand what parents teach their teens when learning to drive as well as why they teach their teens specific skills.

Author Contributions: Conceptualization, J.O.B. and D.G.; methodology, J.O.B., C.J. and D.G.; formal analysis, L.M.; investigation, L.M., J.O.B., C.J. and B.S.; resources, J.O.B. and D.G.; writing-original draft preparation, L.M. and C.J.; writing-review and editing, L.M., J.O.B., C.J., B.S. and D.G.; visualization, L.M.; supervision, J.O.B.; project administration, J.O.B. and D.G. All authors have read and agreed to the published version of the manuscript.

Funding: This research received no external funding.

Acknowledgments: Our heartfelt gratitude goes to the Humphries family and friends for developing the Guard Your Life program to honor Victoria. We would like to thank the BMW Performance Center and the dedicated instructors and logistics staff that offer support this program through their facility and expertise. We are grateful to Shayne McConomy and Roberto Knizek for their assistance with data collection and to the volunteers and supporters of the Guard Your Life program.

Conflicts of Interest: Daniel Gubitosa is employed by the BMW Performance Center. 


\section{References}

1. Simons-Morton, B.; Ouimet, M.C. Parent involvement in novice teen driving: A review of the literature. Inj. Prev. 2006, 12 (Suppl. S1), i30-i37. [CrossRef] [PubMed]

2. Novice Teen Driver Education and Training Administrative Standards (NTDETAS) 2017 Revision; National Highway Traffic Safety Administration: Washington, DC, USA, 2017.

3. Waller, P.F.; Olk, M.L.; Shope, J.T. Parental views of and experience with Michigan's graduated licensing program. J. Saf. Res. 2000, 31, 9-15. [CrossRef]

4. Mayhew, D.R.; Simpson, H.M.; Pak, A. Changes in collision rates among novice drivers during the first months of driving. Accid. Anal. Prev. 2003, 35, 683-691. [CrossRef]

5. Chase, J.C. US state and federal laws targeting distracted driving. Ann. Adv. Automot. Med. 2014, 58, 84.

6. Distracted Driving 2016; Traffic Safety Facts. Report No. DOT HS 812 517; National Highway Traffic Safety Administration's National Center for Statistics and Analysis: Washington, DC, USA, 2018.

7. McDonald, C.C.; Curry, A.E.; Kandadai, V.; Sommers, M.S.; Winston, F.K. Comparison of teen and adult driver crash scenarios in a nationally representative sample of serious crashes. Accid. Anal. Prev. 2014, 72, 302-308. [CrossRef]

8. Simons-Morton, B. Parent involvement in novice teen driving: Rationale, evidence of effects, and potential for enhancing graduated driver licensing effectiveness. J. Saf. Res. 2007, 38, 193-202. [CrossRef]

9. Hartos, J.L.; Eitel, P.; Haynie, D.L.; Simons-Morton, B.G. Can I take the car? Relations among parenting practices and adolescent problem-driving practices. J. Adolesc. Res. 2000, 15, 352-367. [CrossRef]

10. Williams, A.F.; Leaf, W.A.; Simons-Morton, B.G.; Hartos, J.L. Parents' views of teen driving risks, the role of parents, and how they plan to manage the risks. J. Saf. Res. 2006, 37, 221-226. [CrossRef]

11. Sherman, K.; Lapidus, G.; Gelven, E.; Banco, L. New teen drivers and their parents: What they know and what they expect. Am. J. Health Behav. 2004, 28, 387-396. [CrossRef]

12. Washington, S.; Cole, R.J.; Herbel, S.B. European advanced driver training programs: Reasons for optimism. Iatss Res. 2011, 34, 72-79. [CrossRef]

13. Katila, A.; Keskinen, E.; Hatakka, M. Conflicting goals of skid training. Accid. Anal. Prev. 1996, $28,785-789$. [CrossRef]

14. Lund, A.K.; Williams, A.F. A review of the literature evaluating the defensive driving course. Accid. Anal. Prev. 1985, 17, 449-460. [CrossRef]

15. Mynttinen, S.; Gatscha, M.; Koivukoski, M.; Hakuli, K.; Keskinen, E. Two-phase driver education models applied in Finland and in Austria-Do we have evidence to support the two phase models? Transp. Res. Part F Psychol. Behav. 2010, 13, 63-70. [CrossRef]

16. Topolšek, D.; Babić, D.; Fiolić, M. The effect of road safety education on the relationship between Driver's errors, violations and accidents: Slovenian case study. Eur. Transp. Res. Rev. 2019, 11, 18. [CrossRef]

17. Beanland, V.; Goode, N.; Salmon, P.M.; Lenné, M.G. Is there a case for driver training? A review of the efficacy of pre- and post-licence driver training. Saf. Sci. 2013, 51, 127-137. [CrossRef]

18. Gregersen, N.P. Young drivers' overestimation of their own skill-An experiment on the relation between training strategy and skill. Accid. Anal. Prev. 1996, 28, 243-250. [CrossRef]

19. Endriulaitienè, A.; Šeibokaitè, L.; Markšaitytè, R.; Slavinskienè, J.; Arlauskienè, R. Changes in beliefs during driver training and their association with risky driving. Accid. Anal. Prev. 2020, 144, 105583. [CrossRef]

20. Farmer, C.M.; Wells, J.K. Crash and Citation Records of Young Drivers with Skid Avoidance Training; Insurance Institute for Highway Safety: Arlington, VA, USA, 2015.

21. Glendon, A.I.; McNally, B.; Jarvis, A.; Chalmers, S.L.; Salisbury, R.L. Evaluating a novice driver and pre-driver road safety intervention. Accid. Anal. Prev. 2014, 64, 100-110. [CrossRef]

22. Day, M.R.; Thompson, A.R.; Poulter, D.R.; Stride, C.B.; Rowe, R. Why do drivers become safer over the first three months of driving? A longitudinal qualitative study. Accid. Anal. Prev. 2018, 117, 225-231. [CrossRef]

23. Policy Statement and Compiled FAQs on Distracted Driving. Available online: http://www.nhtsa.gov. edgesuite-staging.net/Driving+Safety/Distracted+Driving/Policy+Statement+and+Compiled+FAQs+on+ Distracted+Driving (accessed on 19 June 2020).

24. Mims, L.; Brooks, J.O.; Jenkins, C.; Schwambach, B.; Gubitosa, D. Teen drivers' views of a classroom and closed-road post-license driving program, Guard Your Life. Safety 2020, 6, 44. [CrossRef] 
25. Traffic Safety Facts 2017: A compilation of Motor Vehicle Crash Data; Report No. DOT HS 812 806; National Highway Traffic Safety Administration's National Center for Statistics and Analysis: Washington, DC, USA, 2019.

26. Rhodes, N.; Pivik, K. Age and gender differences in risky driving: The roles of positive affect and risk perception. Accid. Anal. Prev. 2011, 43, 923-931. [CrossRef] [PubMed]

27. Mirman, J.H.; Kay, J. From passengers to drivers: Parent perceptions about how adolescents learn to drive. J. Adolesc. Res. 2012, 27, 401-424. [CrossRef]

Publisher's Note: MDPI stays neutral with regard to jurisdictional claims in published maps and institutional affiliations.

(C) 2020 by the authors. Licensee MDPI, Basel, Switzerland. This article is an open access article distributed under the terms and conditions of the Creative Commons Attribution (CC BY) license (http://creativecommons.org/licenses/by/4.0/). 